\title{
Musical Pasts and Postmodern Musicologies: A Response to Lawrence Kramer
}

\author{
By Gary Tomlinson
}

Early last summer, not long after I was invited by the editors of Current Musicology to contribute to this special issue, the inaugural issue of another music journal landed in my mail box. This was repercussions, produced by graduate students at the University of California at Berkeley. It opened with a position piece by Lawrence Kramer entitled "The Musicology of the Future"-a fitting beginning, given that the journal is devoted to fostering "critical \& alternative viewpoints on music and scholarship" and that Kramer has emerged over the past decade as one of the shrewdest and most theoretically savvy of a younger generation of musical scholars. But Kramer's essay, on closer inspection, was disconcerting. "The Musicology of the Future" seems to me to linger over old viewpoints more than suggest new ones. It reveals patterns of thought that not only already threaten to harden into new orthodoxies of postmodern musicology but that have, at the deepest level, moved little from the putative truths they aim to leave behind. What follows is a brief rejoinder to Kramer's vision of the new musicology.

I should say at the beginning that I do not think Kramer is alone in his difficulty in escaping the old orthodoxies; if he were, my differences with his approach would have no broader resonance than that of a personal disagreement. I sense, instead, that all of us who work in the methodological realms he calls postmodern have experienced this difficulty, that we have all felt twinges of an unease that originates in our sense of the persistent proximity of our methods to those we thought we had moved away from. We have met the enemy and they is us. Kramer's (and our) difficulty touches the heart of our conceptions of the new musicology. For this reason it seems to me that a brief description of some methodological choices that (in my view) underlie his essay and a sketch of some alternative choices might help move the discussion forward.

$$
* * *
$$

Kramer rightly locates the origins of what we may call modernist musicology in nineteenth-century views of the signifying distance between music and words (pp. 7-8). Because of this gap, language was closed off from music; words were "denied access" to its transcendent expressive modes. Those who sought to put the study of music on a scholarly footing were left with two options: positivistic description of historical data around the 
music and analytic description of the workings of the notes themselves. In the first option the experience itself of music was separated off entirely from the scholarly endeavor, while in the second it was transformed, its quasi-religious transcendence sublimated in technical accounts of musical process. Neither option challenged the autonomy and "epistemologically self-contained" character of the musical experience.

But, Kramer notes, this maintenance of music's autonomy does not jibe with the worldliness and contextual contingency that postmodern scholars find in all utterance, musical or otherwise (p. 9). Therefore, "from a postmodern perspective, music as it has been conceived of by musicology simply does not exist." In order to reconceive music (and musicology) in postmodern terms we need not, however, reject the immediacy of its effects on us (p. 10); Kramer would not "show [his] love for music by ceasing to enjoy it." Instead we should abandon the myth of music's autonomy by broadening "the horizons of our musical pleasure" and welcoming the complex situatedness of musical utterances in webs of extramusical forces.

So far, so good. Kramer's diagnosis of the constraints enacted in modernist musicology is smart and eloquent, and his general recommendations are headed in the right direction: toward a new, more flexible contextualization of music and its histories. But in filling out the details of these recommendations Kramer begins to reveal the tenacity of modernist ideology in the new musicology.

Kramer betrays this modernism already when he dubs "criticism" the "rhetorical" and "subjective" language by which we might contextualize music (p. 9). This term, as I have suggested elsewhere, seems in all its many meanings destined to put an ahistorical, aestheticist, sometimes even formalist spin on what might otherwise be conceived as our rich historical encounter of others' musical utterances (see "The Web of Culture: A Context for Musicology," 19th-Century Music 7 [1984]: 350-62). The evocation of criticism, in other words, tends to deal out from the start the most essential and richly problematic historicism of our experiences, musical and other. More on this historicism below.

Kramer reveals his modernism more fundamentally in his next move (pp. 10-11). He locates the context of music-"the densely compacted, concretely situated worlds of those who compose, perform, and listen" that he sees as basic to postmodern perceptions-in the music itself. "The emergence of a postmodernist ... musicology," he writes, "will depend on our willingness and ability to read as inscribed within the immediacy-effects of music itself the kind of mediating structures usually positioned outside music under the rubric of context." Or again, countering Charles Rosen's reading of Mozart's Divertimento K. 563: "What if the music were heard, 
not as the site where its contexts vanish, but precisely as the site where they appear?" Kramer's own example of an alternative musicology-his discussion of the special physicality he hears in K. 563 (pp. 11-16) follows from this question.

This is for me a troubling maneuver. Its effect is to sweep away in a single stroke the epistemological and phenomenological quandaries attendant on the contextualization Kramer has just finished advocating. The many opportunities presented by such thick contextualism are likewise lost, leaving little more than an internalist engagement of the critic with the work. Indeed Kramer unreservedly identifies the "work" as the locus of the new musicology, even though it is one of the modernist categories contested most rewardingly in postmodern thought. In the very moment that he holds out hope for an extramusical broadening of the notes' signifying potential, he draws our attention back to the work, making it the primary (almost exclusive) matrix of its own meanings. Ultimately, I believe, he substitutes modernist internalism and aestheticism, both carrying still the potent charge of nineteenth-century transcendentalism, for postmodern contingency and localism.

In this sleight-of-hand that decontextualizes his contextualism, Kramer falls back on a central tenet of modernist musicology: the sweeping subjective powers of the composer to speak to the critic (analyst, listener in general) through the music. This retrenchment is evident in the example Kramer offers, where Mozart is repeatedly seen to be complicit in "foregrounding" the particular corporeality Kramer senses in K. 563. If we are skeptical, if we wonder where Mozart's music has disappeared to in the questions Kramer asks, we are assured that Mozart himself raises these questions "by making his music behave as it does, and trusting the listener to hear the music within a broader field of rhetorical, expressive, and discursive behaviors." The critic and the composer are perfectly attuned here, speaking to one another without difficulty through the music. Mozart's trust, it would seem, is well placed.

In reading this passage, I for one do not find myself wondering where K. 563 has gone. Mozart's music is simply with us, in one or another of its numberless performative realities, at any moment that we might choose to make it so, and serious thought about music, modernist and postmodern, has always been needlessly plagued by those who exaggerate the fragility of our cultural icons. I wonder, instead, where Mozart has gone-Mozart, a mysterious and elusive subjectivity whom (as Hildesheimer, Solomon, even perhaps Amadeus have begun to show us) we too easily come to believe we know well. Kramer evades the immense complexity of the historian's dialogue with past subjectivities. He offers as the goal of musicology the continuance of "the dialogue of listening," but he gives little hint as to 
how we might begin to reconceive this dialogue in postmodern terms. Indeed, from his example we could only guess that his "dialogue" comes closer to modernist solipsism than to true conversation-to a ventriloquist's monologue in which the critic reacts to the music by throwing his/her voice into the body of the faintly imagined composer/other. It is, finally, Kramer's confidence in his bond with Mozart that rankles here. The inviolate security of his knowledge speaks the language of an older musicology. Instead of postmodern doubt, play, and problematizing of the communicative relation, Kramer offers a too-familiar modernist mastery.

$* * *$

If all this may seem a rather harsh reaction to an essay whose most general anti-modernist intent I certainly applaud, I should repeat by way of melioration what I said at the outset: Kramer's difficulties seem to me to be emblematic of a more general methodological conundrum, of the struggles of a growing number of scholars to forge a musicology genuinely distanced from modernist premises. We are, all of us, in this mess together, notwithstanding the individual differences of method and emphasis that distinguish an Abbate from a Feld, a McClary from an Agawu, a Bianconi from a Subotnik.

The struggle should not discourage the endeavor, of course. It reflects in part the inevitable persistence of well-molded patterns of thought, of disciplinary premises and practices that will only gradually erode. More fundamentally, it reflects the contestatory and self-problematizing stance of postmodernism itself in the face of modernism, a stance that will (we may hope) increasingly decenter and destabilize postmodern musicological discourse even as the nature of this discourse grows clearer. In broad terms, a postmodern musicology will be characterized most distinctively by its insistent questioning of its own methods and practices.

This self-questioning might arise in many areas of our thought. I will suggest four such areas that seem to be, at most, little evident in Kramer's view of the new musicology. These are interrelated places where we might envision musicological premises different from those of modernism or at least find a productive and clarifying tension between those older presumptions and postmodern ones. They are topoi, in other words, that might help to inch us past the gravitational pull of modernist method.

First, we might seek alternatives to the internalism and formalism that have dominated musicology. This is ostensibly Kramer's primary goal. But his insistence on close reading of the notes and his locating of context in them undoes his good intentions. I would go farther than Kramer here and suggest that we need to move away from the whole constraining notion that close reading of works of music, of whatever sort, is the sine 
qua non of musicological practice. This notion has repeatedly pulled us back toward the aestheticism and transcendentalism of earlier ideologies. (I have felt the pull in much of the nascent postmodern musicology I have read and written.) It is not enough to cast our close readings in the light of new methods-narratological, feminist, phenomenological, anthropological, whatever. For it is the act of close reading itself that carries with it the ideological charge of modernism. These new methods, instead, need to be linked to new approaches to music that have distanced themselves from such analytically oriented reading. They need, indeed, to be allowed to engender such new approaches.

Finding alternatives to close reading without forgoing entirely the specific discussion of music they have habitually enabled is a ticklish task, as Kramer's attempt should warn us. Such alternatives might well emerge, I think, from all three of the remaining topoi I will summarize below. But in the most general way I believe they will be discovered in a kind of contextualization different from Kramer's. This contextualism will not circle back narrowly to the notes but instead will resolutely historicize musical utterance, exploding it outwards through an imaginative building of contexts out of as wealthy a concatenation of past traces as the historian can manage. Such contextualism will aim to describe a local set of meanings in as full a volume as possible. It will not pose as a reconstruction of some putative and unitary "original" situation the music inhabited but will recognize the myriad situations we as historians might construct around a musical utterance and the plurality of meanings the music might thus engage. This contextualism will be, like Foucault's archaeology/genealogy, Geertz's anthropology, or Ginzburg's or Chartier's history, a localizing rather than a universalizing strategy. And, in the act of its seeking out its own locale within a plurality of potential meanings, it will incorporate the very "rhetorical" and "subjective" character that Kramer sought in the old haunts of criticism.

Second, we might become more sensitive to realms of musical culture-making beyond the ken of individual, subjective agency. Such agency maintains the modernist myths of genius and inspired, empowered, heroic individualism and supports the reflection of these myths in the omniscient critic (again Kramer's discussion of K. 563 is a useful caution). We cannot successfully challenge these myths while we remain bound to models of culture that see it as made exclusively through the conscious and subconscious intents of historical actors. Neither can we do so while we adhere singlemindedly to conceptions of subjectivity that grant it unrivaled culture-making powers.

The different, metasubjective level of cultural formation that I have in mind moves beyond the reach of individual subjectivities even as they are 
continually implicated in shaping it and being shaped by it. It inhabits the collective, kaleidoscopic, and dialogical realm of subjectivities opened out to one another. It is nothing like the nineteenth century's transcendental Zeitgeist and is distinct even from Annales-school mentalités, because its impact is local, fragmented across larger cultural spaces. Various postmodern methods have aimed to delimit this metasubjective place of cultural formation and to provide a means for describing it: some New Historical writings, Hayden White's tropologies, and, again, Foucault's archaeology/genealogy.

Third, we might try to see more clearly that categories such as "work" "art," "the aesthetic," even "music" itself are not truths given us by the world through which we and others must always conceive musical utterances but rather are themselves cultural constructions darkly tinted for us with modernist ideology. They are concepts that-in the versions of them we habitually and often tacitly deploy-have little currency in the historico-geographical world beyond nineteenth- and twentieth-century westernism. In questioning them we might begin to carry to the heart of our method the limitations of the music-versus-language epistemological model that Kramer identifies as a foundational premise of modernist musicology. It, too, is no monolithic, given truth, but rather a single point, privileged by modern western perceptions, along a spectrum of conceivable relations among music, words, and the world.

In this endeavor the methods employed by post-Foucauldian histories of sexuality and gender might well be revelatory, since such histories have worked hard to show the ways in which some of our most basic, apparently "natural" categories are local cultural constructs. In this endeavor, also, a crucial leverage might come from our exposure to more distant musical others than most of us usually encounter. Our difficulty in seeing beyond modernism is, after all, in part a result of our concentration on the musical adumbrations, avatars, and artifacts of modernism. We need to make central to our studies not only the most familiar musics we come across but also those that seem to us stranger, less tractable. Moreover, we need to bring them into our thoughts not by possessing them as newly minted canonic objects of study - a common enough strategy in the expansion of the observed musical universe that has marked musicology in recent yearsbut by leaving them at a distance and coming into contact with them through the befogged, ambivalent dialogical medium between them and us. We need, in other words, to think hard about what we do as we bring cultural others into our line of vision: how can we construct ways of seeing them that do not aggressively familiarize (colonize, terrorize) them?

Ethnomusicology might seem to be the obvious place to look for help in this endeavor, except that ethnomusicologists have often defined their 
project by transferring onto the musics they study precisely the western presumptions-of internalism, formalism, aestheticism, transcendentalismthat we need to question. (It is significant in this regard that Kramer could turn to a founder of American ethnomusicology, Charles Seeger, in order to exemplify the word/music schism that gave rise to musicological formalism and positivism; see page 7.) With some notable exceptions ethnomusicologists have been less shaken than we might expect by the epistemological revolution that has taken place over the last twenty years in their kindred discipline of anthropology. In ethnomusicology as in musicology, when it comes to constructing postmodern alternatives the enemy seems once more to be us.

Fourth and finally—and perhaps, indeed, most fundamentally—we might begin to interrogate our love for the music we study. This is not to say we should try to stop loving it-I would want this no more than Kramer. It is instead to urge that we dredge up our usual impassioned musical involvements from the hidden realm of untouchable premise they tend to inhabit, and that we make them a dynamic force-to be reckoned with, challenged, rejected, indulged in, whatever-within our study. The nature of our commitment to the works of a Beethoven or a Monteverdi or a Brahms cannot be allowed to lie uninvestigated, for then it imposes its own hegemony, welcoming musics that move more or less like theirs but at the same time foreclosing by invisible action commitments of a similar strength to a thousand other, different musics. This hegemony should be brought to light, examined in order to enrich and complicate our already complex relations with the others we encounter.

In the process we might shift the focus of musicology away from musical utterances all told toward the people who make them, away from Kramer's mastering dialogue between a work and the musicologist toward the less compliant but, I believe, infinitely richer dialogue between people. Then the primary stimulus for musicology, instead of our love for this or that music, might more luminously be our love of, concern for, commitment to, belief in, alienating distance from-choose your words- the others who have made this or that music in the process of making their worlds. Then the study of music-making might open out on the study of world-making.

And then - who knows? - we might even find that Beethoven and Mozart are not so like ourselves-in their conceivable expressive intents, their musical and non-musical desires, their made worlds-as we once thought. At bottom Kramer seems to offer a musicology still conceived as a means to illuminate our own aesthetic experiences. But this it has been for a century now; I am not alone, clearly, in chafing at its constraints. Why not try a musicology that aims instead to problematize the knowledge of others we come to through their musics? 


\title{
Music Criticism and the Postmodernist Turn: In Contrary Motion with Gary Tomlinson
}

\author{
By Lawrence Kramer
}

The problem Gary Tomlinson finds with current efforts to frame a postmodernist musicology is a version of the Cubbins Conundrum. The eponymous hero of Dr. Seuss's classic children's story The Five Hundred Hats of Bartholomew Cubbins is in serious trouble. After taking off his hat to the king, Bartholomew finds himself ordered by the king to-take off his hat. But no matter how often he does so, another, identical hat, a bedraggled old thing with a lame excuse for a feather, keeps appearing on his head. So, too, the musicological Bartholomew (me, in this case) may try to take off the old hat of modernism with the best of intentions, but no better luck.

Tomlinson spots the Cubbins Conundrum in scholarship that seeks a postmodernist end, a "thick contextualism" in the understanding of cultural phenomena, with modernist means. High on the list of such means is criticism, glossed as "close reading" and associated with "internalism," "aestheticism," "formalism," "transcendentalism," and "westernism." Tomlinson claims that criticism trades in concepts, including "[the] work," "art," "the aesthetic," and "even "music' itself," that are "darkly tinted for us with modernist ideology" (p. 23). In place of a critical program, he advocates what we might loosely call an ethnographic one, aimed proximately at "describ[ing] a local set of meanings in as full a volume as possible" (p. 22), and ultimately at knowing, in nonappropriative, nondominating ways, the other people, including our own ancestors, "who have made this or that music in the process of making their worlds" (p. 24).

As Tomlinson acknowledges, he and I share in a desire, fast evolving across our discipline, to uncloister music, to understand it as a worldly activity. No one caught up by that desire could fail to find something appealing in the ethnographic program. But the program as Tomlinson formulates it fills me with misgivings.

First, it depends on a hard-and-fast distinction between criticism and ethnography that may be neither necessary, nor desirable, nor even possible: a programmatic phantom. If so, arguments for either program over the other could easily degenerate into sectarian (or worse, careerist) squabbles.

Second, though it might seem hard to quarrel with the ideal of a knowledge free of tendentiousness, scholars do not have the minds of angels; we are driven to knowledge by more things than we know. The very claim to have such an ideal knowledge might be the surest sign that its absence is 
still the one thing we can be sure of. Even supposing that knowledge and virtue could somehiow be reconciled, can we really mistake the prescriptions and proscriptions of any single epistemic program for a panacea that will reconcile them?

Third, even if the break between modernism and postmodernism is radical, something I think likely despite Jürgen Habermas's arguments to the contrary, ${ }^{1}$ that does not constitute the postmodern as a moment of absolute novelty, a complete rupture with a failed intellectual past. Ironically, the call for such a rupture is a classically modernist maneuver, epitomized by the memorable slogan from Rimbaud's A Season in Hell, "One must be absolutely modern" [Il faut être absolument moderne]. I would say rather that the post- in postmodernism designates the moment of disengagement from the very idea of such absolutes, and of the consequent proliferation of intellectual projects that undo what Jean-François Lyotard calls the "grand metanarratives" and Habermas the "unfinished project" of modern, which is to say post-Enlightenment, reason. ${ }^{2}$

Nonetheless, Tomlinson's critique of criticism cannot merely be written off as a caricature, nor his ethnographic program as a blown-up special interest. On the contrary, the program reflects the pressing need to find the apparent collapse of modernism's cognitive paradigms enabling rather than paralyzing. It is important to work out the possibilities and spot the difficulties of doing this. Similarly, the critique can be taken to spell out exactly what is wrong with one familiar mode of modernist criticism, and even exactly what happens when any mode of criticism goes wrong. And that makes it important to counter the underlying, far more drastic claim that no criticism can ever go right. Perhaps Tomlinson has found the right problems but the wrong solutions. Perhaps he has misconstrued the character of criticism and its relation to a possible musical ethnography. Perhaps he has formulated the ethnographic program itself in terms that will quickly prove their own undoing. And perhaps there is no perhaps about it.

Tomlinson's complaint against criticism is that, in principle, it passes off personal response as knowledge and blinds itself to the otherness for which it presumes to speak. Criticism inevitably sets a reified object before a solipsistic subject. It inflates the authority of both the critic and the artist and establishes a spurious transparency of communication between them, a relay of (pseudo-) knowledge that also acts as a network of disciplinary and social power. The locus of knowledge is the artwork-in this case the music-in which criticism corrals too much of our attention. Fetishizing the work, criticism withdraws us from the real, scants the weight of history, creates a kind of transcendental museum or mausoleum of canonical masterpieces. The locus of power is the figure (person and trope) of the critic. "Close reading" supposedly proceeds from a discursive position that 
involves the a priori assumption of coercive authority: the (im)posture of mastery, an appropriation by the critic of the composer's voice(s), a falsification of knowledge by the denial of the differences between the knower and the known. Tomlinson, accordingly, asks us to lay down our scores. We must no longer "circle back narrowly to the notes but instead . . . resolutely historicize musical utterance, exploding it outwards through an imaginative building of contexts" (p. 22, italics in original).

Tomlinson focuses his objections to criticism on my proposal that we learn "to read as inscribed within the immediacy-effects of music itself the kind of mediating structures usually positioned outside music under the rubric of context."3 Arguing that any such effort is doomed by the blindness inherent in criticism, which "tends to deal out from the start the most essential and richly problematic historicism of our experiences" (p. 19), Tomlinson in effect asks for the reverse, the dispersal into context of what we usually grasp as the immediacy of music. What he wants, if we take him at his word, is music under erasure: a music so decentered, so bought out or bought off by the entrepreneurial historian's "wealthy . . . concatenation of past traces" (p. 22) that we can no longer claim to know it, or claim it as ours to know. In this dispensation there would be no criticism because there would be nothing to criticize; the death of criticism would follow on the death of what we currently think of as music. For some of us that might seem a steep price to pay.

If Tomlinson's terms of understanding are translated into terms of listening, their relentless negativity becomes obvious-and punishing. What would happen if we gave up listening with the kind of deep engagement, the heightened perception and sense of identification, that both grounds and impels criticism? We might avoid a certain amount of ideological mystification-assuming, that is, that mere exposure to ideologically charged representations renders us helpless against them. (Plato thought so, and said we need guardians.) Meanwhile, the materiality of the music, the dynamic sensuous fullness that arguably offers a major site of resistance to ideological pressures, would be put at risk. Can we really hear a music constituted only by its continual flowing outwards into the conduits of world-making? In our unwillingness to fetishize music as an aesthetic object, should we rush to dismantle it into a pure concatenation of signifiers? In pursuit of a credibly modest ethnographic attitude, should we throw the baby out with the bathwater?

If we can avoid an aesthetic ideology only by swapping musica practica for a modern-day musica mundana, if a postmodernist musicology can develop only as a musicology without music, then our situation is pretty grim. On the one side, participation mystique, ideological muddle, cocksure myths of mastery; on the other, the thickets of thick contextualism, 
the Pythagorean mysteries of the ethnohistorian supplanting those of the ethnocentric close reader.

Whatever its failings, criticism at least allows more light and air than that. Criticism is the public record of our sustained, thoughtful involvement with some of the music we find moving, enlightening, provoking, oppressive, ambivalent, and more. Talking about music, old or new, whether under the aegis of individuated works, genres, occasions of performance, improvisation, or social ritual, is a means of investing that music with the very cultural value(s) we also want to comprehend through it. Such talk may risk being solipsistic in practice, but in principle, pace Tomlinson, it is dialogical. As Mikhail Bakhtin argued tirelessly,

Any utterance, in addition to its own theme, always responds (in the broad sense of the word) in one form or another to others' utterances which precede it. The speaker is not Adam, and therefore the subject of his speech itself inevitably becomes the arena where his opinions meet those of . . o other viewpoints, world views, trends, theories, and so forth. ${ }^{4}$

If we take postmodernism to name an affirmative spirit of diversity, a contestable rather than merely a leveling pluralism, then criticism can serve that spirit best not by falling silent, but by foregrounding its own inescapably dialogical and interdiscursive character. Tomlinson complains that Mozart's music is too much with us, but that Mozart, that "mysterious and elusive subjectivity," has (been) disappeared. Granted, the music is very much with the dwindling "us" who still quixotically harbor a love of "classical" music, but is that really because Mozart criticism has continually falsified and appropriated the composer's "musical utterance?" Or is it because Mozart, through his music, has continually provoked dialogical responses that inevitably refigure both "him," each other, and "us?" We may need to recognize that much of our Mozart-talk has been too introverted and too cozy with an imaginary Mozart, but that is no reason either to dismiss it out of hand or, worse yet, to stop talking.

That brings us to the problem of mastery. There can be no denying that criticism has historically promoted a fantasy of instruction in which the critic poses as the master of truth. Tomlinson's forceful, eloquent warning on this point can be only to the good. Not doing criticism, however, is hardly enough to free one of the mastery pose. Certainly neither Tomlinson in his rhetoric nor his discursive models in theirs are free of it; indeed, Michel Foucault, Clifford Geertz, and Hayden White are old hands at mastery, real master masters. And while Tomlinson's positive program for thickly describing the worldly place of music is not only unobjection- 
able, but exciting, his use of that program to proscribe thickly describing the place of worldliness in music is a hegemonic gesture, a gesture of mastery, not of distance or reflection. If Tomlinson really wants to avoid establishing "new orthodoxies of postmodern musicology" (p. 18)-a goal hardly anyone would disavow - he has an odd way of going about it.

Not that this is Tomlinson's problem directly, any more than the Cubbins Conundrum is mine. As he rightly says, we are all in this mess together. The problem is that knowledge and power are in it together, too, as Foucault above all has insisted:

Perhaps ... we should abandon a whole tradition that allows us to imagine that knowledge can exist only where power relations are suspended and that knowledge can develop only outside its injunctions, its demands, and its interests. . . We should admit rather that power produces knowledge, . . . that there is no power relation without the correlative constitution of a field of knowledge, nor any knowledge that does not presuppose and constitute at the same time power relations. ${ }^{5}$

Tomlinson is not to be faulted for promoting a certain mode of knowledge, but for imagining that this mode, and this mode only, can transcend power relations. Underlying this imaginary episteme is the apparent conviction that power always translates into an abusive or appropriative claim of mastery. The conviction is not to be lightly dismissed, given the frequency with which power has done just that. But power and mastery are not necessarily the same thing; the ability to propose knowledge is not necessarily the ability to impose it. There should be-must be-ways of keeping them apart.

Certainly it is questionable whether the critic's discursive position automatically, in and of itself, reproduces the mastery scenario. And even where the scenario occurs, it may include the implicit or explicit acknowledgment of its own fictitiousness. Indeed, one type of postmodernist musicology might be conceived precisely as an attempt to engage musical works, genres, and so on dialogically, to write about them either without assuming the pose of mastery or by deliberately assuming it as a rhetorical position, a discursive trope and not a social or institutional force.

Such an attempt requires a rethinking of what it means to say that the critic "speaks for"-that is, has the power to speak for-a composer or a musical community. Tomlinson conceives this speaking-for as inherently appropriative and ventriloquistic: I speak for myself while pretending to speak for the other. But there are other ways to conceive the process, other "speech genres" within which to situate the critical discourse. In 
speaking of a work by, say, Mozart, I may candidly be speaking for him as an actor speaks for a character in a classic role. I speak for the other precisely in speaking for myself, but always under the possibly resistant impress of the other. Or I may be speaking for Mozart the way a narrator speaks for a character in a novel: again speaking for the other in speaking for the self, but only from a moral or temporal distance that in principle limits my claims to certainty and authority.

Unless I give myself the latitude to speak for the other in some such way, I cannot approach the work (genre, etc.) as an "utterance" at all except as the passive recipient of messages that mean too much or too little. On the one hand I can refer to the most mastery laden concept of all, the paternal word, the authoritative voice of the author. On the other, following Tomlinson, I can depersonalize the utterance altogether, replacing the author with the "metasubjective level of cultural formation . . . beyond the reach of individual subjectivities" (p. 22). That would leave me with a cultural version of the discredited high-structuralist notion that it is language, not the person, which "speaks." Granted, there would be little call to dwell "internally" on utterances not genuinely exchanged between subjects. Such utterances would need thick description to compensate for their wafer thinness. But neutralizing the communicative process does not seem very promising as a means of understanding other people in their world-making.

Tomlinson's will to depersonalization pretty clearly reflects the decentering of the subject that is so prominent a feature of poststructuralist and postmodernist thinking. Even supposing that we can justify the critic's role as dialogical and not ventriloquistic, it is questionable whether we can justify any discursive practice that depends on one unitary, autonomous self speaking for another. Criticism, however, does not require such a dependency. We have already seen that the critic's voice is invested with a certain fictitiousness that can, and perhaps should, be made candid. And the other for whom the critic speaks may be equally provisional, equally embedded in a multiplicity of roles and discourses that no one can hope to master.

For Tomlinson, criticism is simply incapable of these recognitions, as if, paralleling the case with music, the mere representation of "individual, subjective agency" (p. 22) in critical discourse paralyzed our capacities for distance and reflection. Hence Tomlinson would argue that I cannot "close read" music, even for its social character, because in doing so I privilege both the composer as author(ity) over the sociality of musical utterance, and myself as master-a higher author(ity)-over all. We cannot, he argues, challenge "the modernist myths of . . . heroic individualism" (p. 22) in a discourse that perpetuates it. But criticism can do more than merely 
perpetuate the myths of authorship and authority. Precisely because it is historically and rhetorically engaged with those myths, it can also destabilize them, undo them, and experiment with alternatives. Criticism can interrogate both its own myths and the myths of art. And that is something an ethnographic contextualism cannot do by trying to steer around them.

Suppose we were to rely on Foucault's celebrated demystifying thesis that authorship is something produced in and by discourse rather than by an individual subject? Authorship, by this account, is a function, not an ontological privilege. ${ }^{6}$ There is nothing here to derail criticism, but plenty to redirect it. The person who writes (or composes) may at once perform and resist the author-function. And since that function is to personify the conjuncture of discourse and society, the "utterances" produced in its name will everywhere implicate social practices. In that case, I can assuredly make de-authorized social readings of those utterances (say musical ones). Indeed, I can read them prolifically, conceiving their sociality as extending into culture on the one hand and the psyche on the other. Far from privileging me as a master, Tomlinson's "omniscient critic," the presence of such a readable sociality calls me into dialogue with unmasterable realities.

On reflection, then, the opposition between criticism and ethnography proves to be a mirage. Nor is that all. Further reflection will suggest that we cannot even carry out the ethnographic program of thickly contextualizing musical works, styles, or genres without some understanding of their meaningfulness. The knowledge-claims of a dialogical criticism are prerequisite to those of musical ethnography; if either project bans the other, it will suffocate itself.

For if music is really what Tomlinson calls it, "musical utterance," then it must have the speech-act character of utterance. ${ }^{7}$ It must, that is, be able to perform or imitate a social action in the act of being uttered. It must further be able to do this in an indefinite number of different circumstances, and must accordingly be subject to a semantic variability that requires it to be interpreted rather than merely decoded. Only through such interpretation, which is to say, through criticism, the putting into discourse of the dynamic interplay of speaker, utterance, and reply that Tomlinson misleadingly calls internalism, can we make knowledge-claims about musical utterance. And if we decline to make those claims in order to avoid the supposed pitfalls of criticism, we will forgo the chance to recognize the various worldly claims that music makes on $u s-$ and makes precisely through the pleasure that Tomlinson's version of the ethnographic program, in its anti-aesthetic rigor, elides.

In sum, we cannot understand music "in context," thick or otherwise, if we have no means of representing concretely what the music does as 
utterance. Unquestionably, there are political and moral problems with the aesthetic ideologies that have historically furnished those means, but that is no reason to write off the aesthetic, the valorization of perceptual pleasure as knowledge, tout court. One possibility for a postmodernist, which is to say a worldly, aesthetics, is to trace out the interrelations of musical pleasure, musical form, and ideology. Not to pursue that possibility is tantamount to denying-ascetically if not cognitively, but perhaps both - the two cardinal, historically grounded truths that music (or art) is meaningful and that music (or art) gives pleasure.

Tomlinson surely has no wish to make these denials, but his discourse leads implacably in their direction. The reason, I think, is the aversion to old-fashioned subjectivity that everywhere impels his text, and that overlaps imperceptibly into a profound distrust of human agency itself. Schooled in the postmodernist distrust of unitary selfhood and its delusions, Tomlinson's text projects a sense that agency always engrosses too much power, that the subject in action always seeks mastery over something or, worse, someone, as object. Hence his curious assumption that the best means to appreciate someone else's subjectivity is to depreciate one's own. Yet if postmodernism has taught us anything, it is that we do not need to conceive of subjectivity in such Hegelian terms as a force of opposition, inner to outer, private to public, value to fact. We can instead conceive of the subject as a position within a continuous process of communicative exchange, the character of which is simultaneously psychical, social, and cultural. And unless we leave room for this postmodernist subject in the discourses of knowledge, we risk falling back into the worst, most autocratic excesses of instrumental reason.

That is, of course, the last thing Tomlinson wants, but again, his discourse has a will of its own. Despite his sophisticated talk about metasubjectivity and the plural construction of knowledge, Tomlinson's version of musical ethnography is at bottom positivistic. His program appeals to discovery procedures and modes of knowledge uncontaminated by "individual, subjective agency"; it presupposes an oppositional relationship between subjectivity, that is, precisely the partial or localized modes of knowledge that an ethnographic postmodernism is supposed to cultivate, and truth; and it assumes possession of a transparent-enough metalanguage to make good on its epistemic promises. ${ }^{8}$ There are no clear means by which to distinguish this program from what Donna Haraway tartly calls the godtrick of modern epistemology ${ }^{9}$ Underneath the invocation of a "collective, kaleidoscopic, and dialogical realm of subjectivities opened out to one another" (p. 23), I sense, with discomfort, a will to truth that is also a will to both intellectual property and purity. Here those metaphors of a historicism "essential" in character and "rich" in problematicity, of "wealthy" 
concatenations set beyond concepts "darkly tinted" by ideology, make a haunting return. And from these the program reads its proscriptive bias along the ameliorative lines of classic quest romance.

With this turn of argument, I might seem to have thrown Tomlinson's critique back on him in a predictable and somewhat dreary way: You think I'm a crypto-modernist? You're another! But the tu quoque game is not the point. Rather, the point is discovering the best means to carry out the overarching musicological project to which we both want to contribute, the understanding of music in its worldliness. From this standpoint the problem with Tomlinson's version of the ethnographic program is that its distrust of subjectivity sets its conceptual mechanism on self-destruct. The knowledge the program seeks is impossible on the terms it sets.

This is clearest, perhaps, in relation to the problem of otherness. I share Tomlinson's desire not to confuse appreciation with appropriation, but I am not ready to identify the necessary limitations of any one person's discourse, his included, with an appropriative solipsism. Unlike Tomlinson, I am not interested in respecting, not to say reverencing, otherness but in deconstructing the opposition of self and other. For that opposition always posits a superior self-a master. Tomlinson can judge that a critical reading appropriates the otherness of a Mozart or a Monteverdi or a Leadbelly only if he can claim a sure knowledge of that otherness. But since, by his own account, he can arrive at such knowledge only from a position external to the otherness, the claim to knowledge is both a hermeneutic claim and a claim to mastery. Only if Tomlinson could himself be the other could he venture a decisive claim to the knowledge he seeks from the thick context that surrounds the other. But then, since the rest of us remain in a position external to the other, this other Tomlinson would not be able to communicate his claim to us. Of course not: being the other, he would not be empowered to speak for himself, at least to us, and none of us could credibly or transparently speak for him.

At best, I suppose, one might approximate the knowledge Tomlinson seeks by so immersing oneself in the signs of otherness as to identify with it, and then to produce a text that would allow a reader to identify with it. But the text, being a text, would unavoidably be subject to the slippages and metamorphoses of interpretation. And the underlying process of identification would, just as inevitably, lead both the writer and reader into the confusions, alienations, and always questionable jubilances of fantasy, the register of the signifying process that Jacques Lacan calls the Imaginary, and in which desire, not knowledge, is paramount.

Criticism, of course, runs just the same risks, a point that underscores the continuity of criticism and ethnography but also brings us round to the question of conceptual means from a final perspective. How can we 
write criticism without falling afoul of Tomlinson's critique? From my position as a postmodernist critic, the chief value of Tomlinson's argument is that it forces an explicit answer to that question.

How, then, can one write criticism as an agent, a subject empowered to claim knowledge, rather than as a master, a subject privileged to impose knowledge? Or, failing that, how can one write as a literal agent and only a figurative master? I offered one answer (only one, an instance, not a paradigm) in my reading of Mozart's $\mathrm{K}$.563. In his essay, Tomlinson declines to consider the content of this reading. He does so pointedly, of course, true to his critique of critical interpretation as such, but nonetheless with an indirectness that conceals the problematicity of the gesture. And it is indeed odd, if you consult my piece, to speak of internalism, aestheticism, or mastery in relation to a critical discourse that makes no attempt to account comprehensively for form and structure in K. 563 and that continually refers musical events not only to each other but also to the social construction of the body, to labor, to manners, to heterosexuality and homosociality, to the Rousseauvian concept of civil society, and more. This is certainly not close reading in anything like its original literary sense, which defines the "aesthetic object" as a restricted, semi-sacralized field of inquiry and tries to stay wholly within its borders. The critical effort is manifestly to grant no more than provisional authority to any border, to encourage multiple border crossings, and to efface, in the process, the distinctions between inside and outside, work and frame, text and context. One might even suppose that I was resolutely historicizing the musical utterance, exploding it outwards through an imaginative building of contexts-except that I wasn't interested in exploding anything.

Granted, some of the differentness of K. 563 will necessarily be lost in my discourse. But the loss might have its compensations in insight, and, in any case, if I do not write critically, all of the differentness of K. 563 as discourse will be lost. There is no musical utterance without an interlocutor; there is no context without a text. Jacques Derrida made this same point with the famous dictum that there is no outside the text. But we should remember that the dictum is credible only because there is no inside the text, either. With luck, each critical effort that puts this recollection into practice will count as a step toward collapsing the ideal(ology) of appropriation, disrupting the trade in authority, mastering the seductions of mastery.

These goals are reachable, if no more than asymtotically, only by writing onward. In other words, the solution to the Cubbins Conundrum is to play it out to the end. When Bartholomew does that, he saves himself, and incidentally triumphs over arbitrary authority, by taking off so many hats that a metamorphosis happens. After 450 doublings, his hats spontane- 
ously begin to blossom; the poor excuse for a phallocratic feather exfoliates into lush ambiguous plumes and gorgeous gems. But Bartholomew, good postmodernist that he is, refuses to fetishize his new headwork. He produces splendid hats at last, but keeps none of them.

\section{NOTES}

1 Jürgen Habermas, The Philosophical Discourse of Modernity: Twelve Lectures, trans. Frederick G. Lawrence, Studies in Contemporary German Social Thought (Cambridge: MIT Press, 1987).

2 Jean-François Lyotard, The Postmodern Condition: A Report on Knowledge, trans. Geoff Bennington and Brian Massumi, Theory and History of Literature, 10 (Minneapolis: University of Minnesota Press, 1984); Habermas, Philosophical Discourse of Modernity.

3 “The Musicology of the Future," repercussions 1 (1992): 10.

4 Mikhail Bakhtin, Speech Genres and Other Later Essays, ed. Michael Holquist, trans. Vern McGee, University of Texas Press Slavic Series, 8 (Austin: University of Texas Press, 1986), 94.

5 Michel Foucault, Discipline and Punish: The Birth of the Prison, trans. Alan Sheridan (New York: Vintage Books, 1979), 27.

6 Michel Foucault, "What is an Author," in his Language, Counter-Memory, Practice: Selected Essays and Interviews, ed. Donald F. Bouchard, trans. Donald F. Bouchard and Sherry Simon (Ithaca: Cornell University Press, 1977), 113-38.

7 For a fuller account of the speech-act character of music, see my Music as Cultural Practice: 1800-1900 (Berkeley: University of California Press, 1990), 6-15. J. L. Austin's term speech-act can be taken to indicate both the class of "performative" utterances, those that do something in being said, and the performative dimension (or "illocutionary force") of utterance in general.

8 Tomlinson is aware of the metalanguage problem, but tries to dispose of it in a single sentence: "In the act of its seeking out its own locale within a plurality of potential meanings, [ethnographic contextualism] will incorporate the very 'rhetorical' and 'subjective' character that Kramer sought in the old haunts of criticism" (p. 22). This statement is problematical at best. The contextualist discourse is said to be both inside its locale (the locale is its own) and outside it (the locale must be sought out). The externality gives the discourse the status of a metalanguage. The internality is somehow supposed to mitigate this status without disrupting it; hence the figure of incorporation. But the mitigation goes too far. On what terms can the discourse incorporate rhetoricity and subjectivity without being constrained and impelled by them?

9 Donna Haraway, "Situated Knowledges: The Science Question in Feminism and the Privilege of Partial Perspective," in her Simians, Cyborgs, and Women: The Reinvention of Nature (New York: Routledge, 1991), 193. 
I resist the many imperatives, the either/or dualisms, the all-or-nothing propositions, and the implacable teleologies Kramer folds into my views. In the face of so systematic a rigidification of my ideas I will be brief but needfully repetitive.

Kramer writes of my "hard-and-fast distinction between criticism and ethnography" (p. 25). I wrote of criticism as a force that "tends to deal out from the start the most essential and richly problematic historicism of our experiences" (p. 19). Music criticism and music history have in my view been countervailing but intersecting tendencies; they admit no absolute distinction.

Kramer would avoid "sectarian (or worse, careerist) squabbles" (p. 25) while still somehow-mysteriously, by my lights-taking full cognizance of the play of power in discourse. I see criticism as a set of approaches whose structures of institutional validation push it in certain methodological directions more forcefully than in others. What Kramer dismisses as sectarian squabbles are, it seems to me, at the center of our differences. Which is only to say the obvious: Kramer's choice to pursue "criticism," like mine to pursue "history" or "ethnography," carries heavy ideological/institutional/disciplinary baggage along with it. We might profit by looking deeper into the baggage.

Kramer imputes to me the "drastic claim that no criticism can ever go right" (p. 26). Again, I spoke of tendencies, not absolutes: I suggest that because of its institutional history criticism tends to pull us away from the rich inherent dialogism of all utterance (on which Kramer and I agree; no need for poor Bakhtin to sit up nights) in the direction of a narrowed dialogue or even solipsism.

Kramer sees me as depicting, in "classically modernist" fashion, "the postmodern as a moment of absolute novelty" (p. 26) ${ }^{1}$ I spoke instead of anything but a sharp break between modernism and postmodernism: of a widespread "unease" I sense at "the persistent proximity of our methods to those we thought we had moved away from"(p. 18) and of "the contestatory and self-problematizing stance of postmodernism ... in the face of modernism"(p. 21). I use "postmodern" the way Terry Eagleton uses "postRomantic": we are products of modernism "rather than confidently posterior to it."

In Kramer's reading I seek "music under erasure" and pursue a relentlessly negative "postmodernist musicology . . . without music," even "the death of what we currently think of as music"(p. 27). This is not the first time that challenges to conventional analytic and critical approaches to music have been branded anti-aesthetic (read: anti- or unmusical). The 
knee-jerk response itself says a lot about our inability to disengage ourselves even a little from, not all "deep engagement"(p. 27) with music, but a particular kind of an aesthetic engagement defined and created in eighteenth- and nineteenth-century Europe. The ideology of this engagement still weighs too heavily, in my estimation, on the academic study of musics.

The erasure of music I advocate-that is, musique sous rature in a truly deconstructive rather than Kramer's merely destructive guise-might allow us to unfold the cultural experiences we gather under the rubric "music" as a patchwork of divergences supporting and simultaneously undermining our presumptions rather than as a monolothic sameness. It might begin to expose ways in which our musical languages and our languages about music bear within themselves, to speak in Derridean terms, a call for their own critique. It might help bring to light deep metaphysical myths on which our musical and musicological practices have been based. The dearest price musicology can pay is not a decentering of our current notions of music - this ought to be its steadfast aim-but the continued sacrifices of musical invitations to a broad engagement in human difference.

The erasure of music I have in mind, by the way, would not militate against all close study of scores but only against the preeminence it claims in most current varieties of musicological research and pedagogy. I believe that dislodging this close study from its position as what I called "the sine qua non of musicological practice" would help us to a fuller awareness of the premises it usually entails. More generally, I don't wish to "proscribe" (Kramer's word, p. 29) any approaches but rather to apply new pressures, to scrutinize marginal traces, to look sometimes elsewhere.

Kramer is apparently troubled by my notions of metasubjective historical exploration. He devotes a good portion of the midsection of his response to the refutation of my putative "will to depersonalization" ( $p$. 30 ), to the "aversion to old-fashioned subjectivity that everywhere impels" my text, and to my "profound distrust of human agency itself" (p. 32), suggesting in the process that I adopt "high-structuralist" ideas. Here Kramer confuses any notions of metasubjective cultural formation with an aggravated Lévi-Straussianism that sees nothing but metasubjectivity. The confusion is old hat by now; Foucault needed to combat it already in the late 1960s. Indeed Foucault's archaeological/genealogical project as it evolved around 1970 may be conceived from this perspective as an effort to strike a precarious balance of subjective and metasubjective modes of cultural formation and analysis in the face of exacerbated structuralist/ anti-structuralist polarities around him. (In any case, Kramer's rejection of metasubjective historical inquiry is ironic in light of the precisely metasubjective "will of its own" he ascribes to my discourse on p. 32.)

In my own brief discussion of metasubjective research aims I urged that 
we loose ourselves from models that see culture as the exclusive product of conscious and subconscious subjectivity (p. 22). This point is one of four suggestions I offered for a revised musicology (pp. 21-24); all the other three are intricately implicated in models of subjectivity and intersubjectivity. I have never shied away from analyses of human agency in my work. Indeed I have argued repeatedly that invocations of the intentional fallacy and other interpretive stances that place out of bounds questions of historical subjectivity are simplistic, misleading, and limiting. And my recent book Music in Renaissance Magic is largely concerned with reconciling certain subjective (hermeneutic) and metasubjective (archaeological) analyses.

Neither have I ever relinquished "the latitude to speak for the other" Kramer discusses on page 30 . In fact I believe we might well take, as a baseline characterization of our interpretive speech-acts, Kramer's formulation that we speak for the other in speaking for ourselves, "but always under the possibly resistant impress of the other" (the echo resounds here of latter-day hermeneutic formulations like Paul Ricoeur's famous "comprehension of the self by the detour of the comprehension of the other"). ${ }^{3}$ Except that I'm disturbed by the potential slippage from Kramer's "always" to his "possibly." The resistance of others in our speech is indelible and inevitable, hard-wired into language, so to say. (Wake up, Mikhail!) The problem, then, is how to take greater cognizance of this ubiquitous resistance, how to carry language's play of différance, of unmasterable traces, to the heart of our historical method as an ongoing critique of our strategies of mastery. My suggestions for revising our musicological project aimbriefly, generally, and preliminarily, to be sure-in this direction.

So when Kramer ascribes to me "the ideal of a knowledge free of tendentiousness" (p. 25), when he argues that I ignore my own masterful moves or those of Foucault, Geertz, et al., when he accuses me of advancing my "ethnographic" mode of understanding as the only one that "can transcend power relations" (p. 29), I can only doff, Cubbins-ish, another hat in the hope that my head will be more clearly revealed. So let me be as clear as I can: My suggestions are all predicated on the idea that we are exercizing our powerful and "rancorous will to knowledge" (Nietzsche/ Foucault) whenever we speak or teach or set pen to paper or fingers to computer keyboard. In this I disagree with Kramer (p. 29): I think the subject-positions we find as scholars $d o$ automatically "reproduce the mastery scenario," and I do not find Kramer's "speech genres" responsible answers to the ethical problems entailed in these masterful claims. I seek an ethnographic historicism that, in Foucault's words, "is capable of liberating divergence and marginal elements-the kind of dissociating view that is capable of decomposing itself, capable of shattering the unity of man's being through which it was thought that he could extend his sover- 
eignty to the events of the past." I want a historical method that; instead of clamoring ever louder, will undermine and moderate its own voice through its clearer (but never full) hearing of others; a method in which the subject-position we adopt is not an a priori and little-conscious presumption subsequently ignored but the conscious, problematized material medium we inscribe at every moment of making history. I believe we might move toward such a historicism through the specific reorientations I suggested in my response to Kramer, among others, and, more generally, through an intricate construction of webs of historical traces (musical and extramusical) aided by genealogical, dialogical, deconstructive and postdeconstructive, feminist, and postcolonial conceptions of culture, knowledge, and power.

If Kramer's criticism is really an intersubjective practice of "putting into discourse . . . the dynamic interplay of speaker, utterance, and reply" (p. $31)$; if it aims in its historicism and rhetoricality to destabilize our myths (p. 31); if its "effort is manifestly to grant no more than provisional authority to any border, to encourage multiple border crossings, and to efface, in the process, the distinctions between inside and outside, work and frame, text and context" (p. 34); then perhaps I have little substantive quarrel with him.

The trouble is that his practice of criticism, along with the practices of many other scholars, seems to me rarely to square with these ideals. It does not seem to be destabilizing of itself, rather the reverse. It does not sufficiently put its own world in jeopardy, to paraphrase James Clifford, as it depicts the worlds of others. ${ }^{5}$ In this it threatens to efface more than the distinctions of work and frame or text and context; it threatens to efface the distinction of self and other all told. Kramer writes: "I am not interested in respecting, not to say reverencing, otherness but in deconstructing the opposition of self and other" (p. 33). But there is a danger in such an approach, the danger that even deconstruction's powerful critique of western language metaphysics will serve only to bolster or reinstate old patterns of dominance; the danger that, as Homi Bhabha warns, "the place of otherness [will be] fixed in the west as a subversion of western metaphysics and . . . finally appropriated by the west as its limit-text, anti-west." Postmodern thought at its most challenging, it seems to me, pursues something else: the extraordinarily complex and problematic maintenance of a space for others' escape from our patterns of meaningfulness at the very moment in which we, interacting with them, masterfully map out those patterns.

Enough. More than enough. We both, Kramer and I, write books, and have published ones recently that, if not the last words on our approaches, at least give a clearer sense of their differences in practice than will be had 


\section{Current Musicology}

from this exchange. Readers who care to follow these differences might well turn to Music as Cultural Practice and Music in Renaissance Magic. Censeat lector.

\section{NOTES}

1 Cf. Andreas Huyssen's warning: "Where postmodernism simply jettisons modernism it just yields to the cultural apparatus's demands that it legitimize itself as radically new, and it revives the philistine prejudices modernism faced in its own time." "Mapping the Postmodern," in After the Great Divide: Modernism, Mass Culture, Postmodernism (Bloomington: Indiana University Press, 1986), 185.

2 Terry Eagleton, Literary Theory: An Introduction (Minneapolis: University of Minnesota Press, 1983), 18.

3 Paul Ricoeur, Le conflit des interprétations. Essais d'herméneutique (Paris: Editions de Seuil, 1969), 20.

4 Michel Foucault, "Nietzsche, Genealogy, History," in Language, Counter-memory, Practice: Selected Essays and Interviews, ed. Donald F. Bouchard (Ithaca: Cornell University Press, 1977), 153.

5 James Clifford, "On Ethnographic Authority," Representations 2 (1983): 133.

6 Homi K. Bhabha, "The Other Question: Difference, Discrimination, and the Discourse of Colonialism," in Literature, Politics and Theory: Papers from the Essex Conference 1976-84, ed. Francis Barker, Peter Hulme, Margaret Iversen, and Diana Loxley (New York: Methuen, 1986), 151. 